NBER WORKING PAPER SERIES

S'TICKY PRICES, MONEY AND BUSINESS FLUCTUATIONS

Robert G. King

Joseph G. Haubrich

Working Paper No. 1216

NATIONAL BUREAU OF ECONOMIC RESEARCH

1050 Massachusetts Avenue

Cambridge, MA 02138

October 1983

Support from the National Science Foundation is acknowledged. The research reported here is part of the NBER's research program in Economic Fluctuations. Any opinions expressed are those of the authors and not those of the National Bureau of Economic Research. 


\section{Sticky Prices, Money, and Business Fluctuations}

\section{Abstract}

Can nominal contracts make a difference for the neutrality of money if these arise endogenously in general equilibrium? This paper utilizes a version of Lucas's seminal equilibrium business cycle theory to address this question. However, we depart from Lucas in assuming that (i) agents have complete information about the money stock; (ii) fundamental shocks to the system are purely redistributive and private information; and (iii) moral hazard precludes conventional insurance markets. With an exogenous restriction on contracts, money is fully neutral. But, when this restriction is lifted, efficient risk-sharing between suppliers and demanders leads to a potential nonneutrality of money. In particular, if an increase in the money growth rate signals a rise in the dispersion of shocks to demanders' wealth, then prices adjust only partially to monetary shocks and there is a positive association between money and output.

Robert G. King Department of Economics University of Rochester Rochester, NY 14627 (716) $275-3895$
Joseph G. Haubrich Department of Economics University of Rochester Rochester, NY 14627 (716) 275-2255 
Most macroeconomists believe that some form of price stickiness underlies the observed positive association of high money growth and high real activity. Not infrequently, this price stickiness is asserted to arise from explicit or implicit contracts. Consequently, model economies that do not include nominal contracts are viewed as omitting the basic cause of monetary nonneutrality. For example, Lucas's (1972) pathbreaking general equilibrium model of business fluctuations-which employs imperfect aggregate information to generate monetary nonneutrality--has been widely criticized for omitting nominal contracts, even though no economic forces would lead these to arise endogenously. Yet, in the past decade, no similarly explicit model economy has been produced that derives a role for nominal contracts from underlying assumptions about the economic environment and explains the implications of contract arrangements for money and business cycles. ${ }^{1}$

The present paper provides a simple rational expectations general equilibrium model in which endogenously generated contracts make a difference. That is, under one fiscal-monetary regime, contracts simultaneously make prices sticky--responding less than proportionately to changes in the quantity of money--and lead to a causal positive relationship between contemporaneously observed money and production/effort. Further, our model economy is a variant of Lucas's (1972) setup, so that monetary changes are neutral in the absence of contracts because economic agents accurately perceive these changes.

1 In a modification of Lucas's (1972) setup that incorporates entrepreneurs and relatively risk averse workers, Azariadis (1980) demonstrates that endogenous labor market risk allocating arrangements-which require an enforceable contingent contract--may enhance the real effects of imperfectly perceived nominal disturbances. Efficient ex ante arrangements in Azariadis's (1980) setup do not permit real quantities--hours worked or total compensation--to depend on contemporaneously perceived monetary disturbances. 
These results derive from the following underlying assumptions about the preferences, technology and information structure of a stochastic consumption loans model that is in most other ways identical to the full information version of Lucas's (1972) setup. First, risk averse demanders of money are subject to idiosyncratic individual disturbances, that are private ${ }^{2}$ information. That is, there is a demand for insurance against idiosyncratic disturbances but moral hazard rules out operation of conventional insurance markets. Second, the growth rate of money is positively associated with the dispersion of individual disturbances. Third, prior to the realization of money growth or individual shocks, suppliers of goods can compete by offering alternative contracts that specify a relationship between money growth and price adjustments. Fourth, the technology of exchange dictates that an individual visit only one supplier after realization of aggregate and individual disturbances.

Efficient competitive contracts embody a shifting of risk, with resources being transferred from suppliers to demanders in contingencies that involve high individual uncertaingy and vice versa. That is, as money growth is an indicator of the extent of individual uncertainty, prices rise less than proportionately and production/effort expands when money growth is high. Symmetrically, prices fall less than proportionately and production/effort contracts when money growth is $10 \mathrm{w}^{3}$

2 In our formal model, we view these as random transfers of real goods from a central government but these might alternatively arise from a varicty of entironmental sources.

3 Our model economy thus illustrates a general principle, discussed in more detail by Haubrich (1983), concerning price movements in model economies that have (i) incomplete insurance due to moral hazard and (ij) contractural exchange contingent on aggregate variables. The general principle is that aggregate disturbances may have different qualitative effects on near-representative agent economies with and without contracts if these aggregate shocks alter the dispersion of individual circumstances. 
The srganization of the remainder of the paper is as follows. In section I, the basic structure of the model is outlined. Competitive equilibrium without contracts is discussed in section II and that with contracts is developed in section III. Section IV is a summary and conclusions.

\section{The Structure of the Economy}

In this section, we outline a stochastic consumption loans model that draws heavily on Lucas (1972). Each period, $\mathrm{N}$ identical individuals are born, each of whom lives for two periods. In the initial period of the life cycle, effort is supplied in amount $n$ and goods are consumed in amount $c$. In the latter period, goods are consumed in amount c'. Each individual's preferences for consumption and leisure are given by utility function:

$$
u(c, 1-n)+v\left(c^{\prime}\right)
$$

Following Lucas, we assume that (i) $u$ is increasing in consumption and leisure, strictly concave and twice continuously differentiable; (ii) $v$ is increasing, strictly concave and twice differentiable; (iii) u is restricted so that current consumption and leisure are not inferior goods; and (iv) agents' preferences are the expected value of (1) under situations of uncertainty. In addition to Lucas's preference assumptions, we require that old age marginal utility is convex, which implies a particular behavior toward uncertainty discussed in detail below.

Grossman, Hart, and Haskin (1982) also discuss the role of aggregate shocks as signals about unobservable individual disturbances which we focus on here. However, they focus on economies where asymmetric information between firms and workers is key and do not explore the neturality of money to any important degree. 
Production takes place according to the simple scheme utilized by Lucas (1972). That is, one unit of effort yields one unit of output within the period but goods are not storable.

There are a large number of islands (indexed by $k=1,2, \ldots K$ ) in which productive activity takes place. In each period of the discrete time structure (indexed by $t=0,1 \ldots$ ), it is physically possible to transact (produce or consume) in only one of these market places. In each period, $\mathrm{J}=$ $N / K$ agents of each generation are presumed to transact in each market (in equilibrium). In contrast to Lucas, there are no exogenous shifts in demand across markets (caused by a random distribution of traders) and agents are fully cognizant of the terms of trade in other markets (although this information has no value in our setup). We discuss the importance of market structure further below.

The basic source of uncertainty in our model is a random old-age transfer payment. That is, each old agent receives a transfer that has commodity value $\varepsilon$. Within each is land, we require that transfers aggregate to zero,

$$
\sum_{j=0}^{J} \varepsilon_{j}=0,
$$

in each period so that transfers are purely individual uncertainty. We assume that $\varepsilon$ realizations are private information, so that moral hazard precludes conventional insurance arrangements. This source of uncertainty is absent in Lucas (1972) and is a key ingredient of our model.

Money serves as an intergenerational store of value in the consumption loans model. As in Lucas (1972), we assume that money is governed by

(2) $\quad m^{\prime}=m x$. 
That is, over a period, the money stock (m) grows at a stochastic rate (given by $x-1$ ), which is distributed as proportionate transfers to the holders of money (the elder generation) and, hence, is spent. We assume that $x$ is serially independent with mean $x$. During the period, in contrast to Lucas, al1 agents are presumed to know the values of $\mathrm{x}$ and $\mathrm{m}$, which are the aggregate state variables of the model.

Table 1 should make clear the time structure of activities within each period. At the beginning of the period, prior to realization of shocks, old agents make locational decisions. In the contractural version of our model, this is the interval in which young agents in a specific market offer contracts with the aim of attracting of demanders. Subsequently, realization of $\mathrm{x}$ and $\varepsilon$ takes place followed by production and consumption.

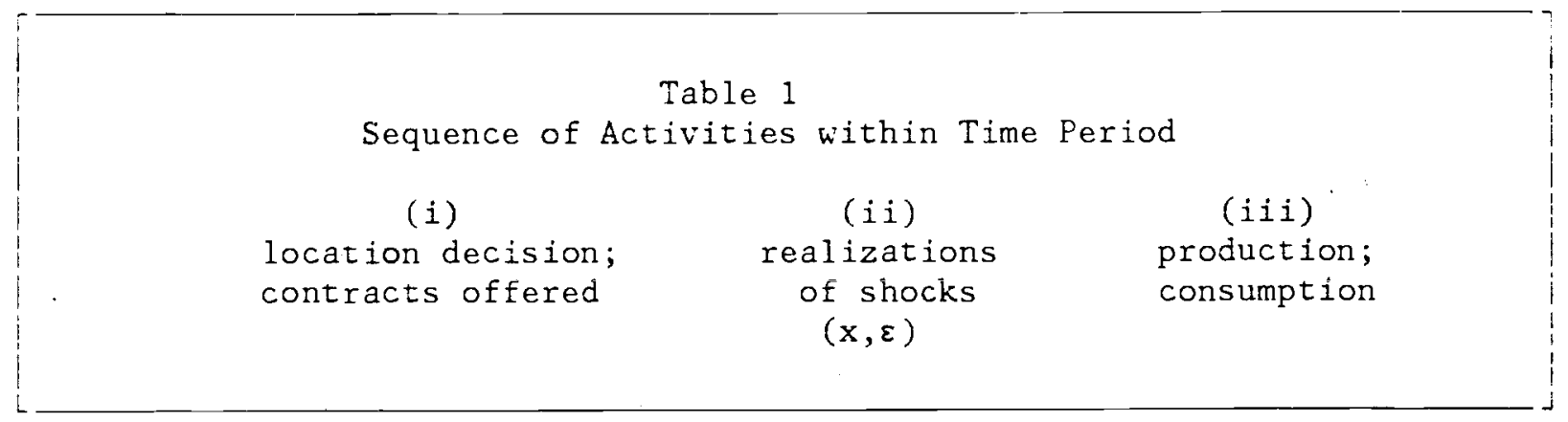

II. Competitive Equilibrium without Contracts

In this section, the nature of competitive equilibrium without contracts is analyzed. Since this analysis is close to a special case of Lucas (1972), our treatment will be brief and focus on developing material useful for subsequent discussion. 
Supply and demand for goods versus money will determine the price level in our economy. The market-clearing value of this price (in any of the $\mathrm{K}$ identical islands) may be written as a function of the state of the economy $(x, m)$.

(3) $\quad \mathrm{p}=\psi(\mathrm{x}, \mathrm{m})$

Our analysis follows Lucas (1972) in investigating the nature of this equilibrium price function." Only young agents face a nontrivial decision problem, i.e., the old simply spend their accumulated cash balances. The young must pick levels of consumption (c), effort ( $n$ ), and money demand/saving ( $\lambda$ ) so as to maximize expected utility, i.e.,

$$
\begin{aligned}
& \max \left\{u(c, 1-n)+E v\left(c^{\prime}\right) \mid x, m\right\} \\
& \text { s.t. } p(n-c)-\lambda \geq 0 \\
& \lambda x^{\prime}+\varepsilon^{\prime} p^{\prime}-c^{\prime} p^{\prime} \geq 0,
\end{aligned}
$$

where $E() \mid x, m$ denotes an expectation of a variable conditional on $x$ and $m ; \lambda$ is nominal money demand; $\mathrm{p}^{\prime}$ is the future price level,etc.

It is useful solve this maximization problem in two stages. First, consider picking efficient quantities of leisure and current consumption so as to maximize utility given a specific pattern of saving behavior. The result of this maximization process is an indirect utility function and conditional demands for goods and leisure (or, equivalently, a supply of effort).

$$
w\left(1-\frac{\lambda}{p}\right)=\max \{u(c, 1-n)\} \text { s.t. } n-c-\lambda / p \geq 0
$$
4 We follow Lucas(1972) in restricting attention to stationary price
functions. 
(6) $\quad c=\phi_{c}\left(1-\frac{\lambda}{p}\right)$ and $n=\phi_{n}\left(1-\frac{\lambda}{p}\right)$.

Previous assumptions imply that $w$ is twice continuously differentiable and that $\phi_{C}$ and $\phi_{C}$ are continuously differentiable. The assumption that consumption and leisure are normal goods implies that $\mathrm{D} \phi_{\mathrm{C}}>0$ and that $\mathrm{D} \phi_{\mathrm{n}}<$ 0.5 Second, consider selecting an efficient savings plan $(\lambda / p)$ so as to maximize

$$
w^{\prime}\left(1-\frac{\lambda}{\mathrm{p}}\right)+\operatorname{Ev}\left(\frac{\lambda}{\mathrm{p}} \cdot \mathrm{R}^{\prime}+\varepsilon^{\prime}\right) \mid \mathrm{x}, \mathrm{m}
$$

where $\mathrm{R}^{\prime}=\mathrm{px}^{\prime} / \mathrm{p}^{\prime}$ is the real return on money. The intertemporal efficiency condition for this plan is simply

$$
-D w+E\left[D v \cdot R^{\prime}\right] \mid x, m=0
$$

which states equality between current utility foregone with a unit of saving $(\lambda / p)$ and future utility received.

Individual income uncertainty ( $\left.\varepsilon^{\prime}\right)$ will plausibly raise the demand for saving as a 'hedge', under conditions on $v$ discussed by Sandmo (1970). Such behavior is ensured if old age marginal utility is convex $\left(D^{3} v>0\right)$, which is implied by absolute risk aversion that diminishes with $c$. That is, savings will rise with greater second period income uncertainty so long as the premium an individual must be paid to accept a fixed actuarially fair bet declines with the level of future consumption ( $\left.c^{\prime}\right)$. Thus, in comparison to Lucas's setup--which involves no idiosyncratic income shocks-there will be more desired saving $(\lambda / p)$ at any rate of return $R^{\prime}=\left(\mathrm{px}^{\prime} / \mathrm{p}^{\prime}\right)$. In competitive equilibrium, money supply (xm) must equal money demand ( $\lambda$ ). Requiring (7) to

5 he use the symbol "D" to denote a partial derivative, with a subscript $i$ indicating the derivative of a function with respect to its ith argument and a superscript $\mathrm{j}$ indicating the jth partial derivative. 
hold with $\lambda=x m$, it is direct that the price level is proportional to the money stock in competitive equilibrium, i.e., $p=\psi \mathrm{xm}$.

$$
\operatorname{Dw}\left(1-\psi^{-1}\right)=E\left[D v\left(\psi^{-1}+\varepsilon^{\prime}\right)\right] \mid x, m
$$

Equilibrium is unique, following Lucas (1972, pp. 112-113), because tine lefthand side of (8) is decreasing in $\psi$ and the right-hand side in increasing in $\psi$

The competitive equilibrium without contracts involves a neutrality of money as in Lucas (1972) because agents have accurate information on the money stock. Prices adjust proportionately to money shocks. ${ }^{6}$ The micro ievel uncertainty leads to greater saving than that in Lucas (1972), under our (plausible) assumption, so that the price level is lower, reflecting a greater demand for money as a hedge against future income uncertainty. But, realizations of these micro disturbances have no effect on the price ievel, although they do reallocate consumption across members of the elder generation.

\section{Competitive Equilibrium with Contracts}

At the beginning of each period, prior to the realization of aggregate and individual shocks, we now permit the representative young agent in each market to offer a contingent contract (it is best to view suppliers as bundled together into a firm so that no idiosyncratic demand risk is present). Specifically, we consider contracts that permit a demander to buy any guantity at the price

\footnotetext{
5 McCallum (1983) notes that this result derives from two facts: ii money growth is permanent and $(i i)$ the proportionate distribution oi nei money effectively gives money a positive nominal return.
} 
(9) $\quad \mathrm{p}=\pi(\mathrm{x}) \mathrm{m}$

where the "price contract" i.e., the function $\pi(x)$, is chosen by suppliers so as to maximize their liferime expected utility subject to competition. That is, by deciding to attend the market in question, demanders must achieve a level of expected utility at least equal to that achievable elsewhere (v). Since a demander decides on a market prior to realization of $x$ and $\varepsilon$, the relevant constraint is thus

$$
E\left\{v\left(\frac{M^{\prime}}{p}+\varepsilon\right)\right\} \geq \bar{v}
$$

The presence of a large number of markets permits us to reasonably treat $\bar{v}$ as not influenced by the contract offered by the market in question.

Given the setup of the model, per capita demand takes the same simple form under a contracts regime that it did previously, i.e., $\mathrm{m}^{\prime} / \mathrm{p}=\mathrm{xm} / \pi(\mathrm{x}) \mathrm{m}=$ $x / \pi(x)$, except that $\pi(x)$ is now viewed as an object of choice by the supplier. hie continue, however, to view suppliers as treating the distribution of future prices as invariant to their current actions, i.e., taking the form $\mathrm{p}^{\prime}=$ $\pi^{\prime}\left(\mathrm{x}^{\prime}\right) \mathrm{m}^{\prime}$, where $\pi^{\prime}$ is not an object of choice. Irrespective of the realization of $x$ and choice of $\pi(x)$, the representative young agent will receive $m$ ' units of money, which will be held over until next period, yielding expected utility,

$$
E v\left(c^{\prime}\right)\left|x, m=E v\left(\frac{x^{\prime}}{\pi^{\prime}\left(x^{\prime}\right)}+\varepsilon^{\prime}\right)\right| x, m,
$$

where the second equality derives from using $c^{\prime}=\left(\mathrm{m}^{\prime} \mathrm{x}^{\prime} / \mathrm{p}^{\prime}\right)+\varepsilon^{\prime}$ and $\mathrm{p}^{\prime}=$ $\pi^{\prime}\left(\mathrm{x}^{\prime}\right) \mathrm{m}^{\prime}$. 
Thus, optimal contract choice is separate from optimal savings in our model economy. An efficient contract may be found by maximizing expected young agent utility (11) with respect to $\pi(x)$, subject to the demand constraint.

$$
\begin{aligned}
& \max E\left\{w\left(1-\frac{x}{\pi(x)}\right)\right\} \\
& \text { s.t. } \operatorname{Ev}\left(\frac{x}{\pi(x)}+\varepsilon\right) \geq \bar{v}
\end{aligned}
$$

It is possible to express this maximization problem as a control problem with an integral constraint so long as $x$ is continuously distributed (see the appendix for details). The key necessary condition for an optimal price policy is our model's version of Borch's (1962) rule for efficient risk sharing. That is, it must be that

$$
\operatorname{Dw}\left(1-\frac{x}{\pi(x)}\right)=\alpha E\left[D v\left(\frac{x}{\pi(x)}+\varepsilon\right)\right] \mid x
$$

at each point on range of $x$, where $\alpha$ is the value of the multiplier attached to the constraint in (11) above. This expression states equality (in each aggregate state $x$ ) of the costs and benefits of transfers between the contracting parties. To examine how contract prices move in response to changes in $x$ (i.e., as one moves along the range of $x$ realizations), we totally differentiate (12) and rearrange terms, yielding

$$
\frac{d \log \pi(x)}{d \log x}=(1-a)
$$

where $a=\left\{\alpha \pi(x) \int D r D_{2} g(\varepsilon ; x) d \varepsilon\right\} /\left\{-D^{2} w-\alpha E\left[D^{2} v\right] \mid x\right\}>0$. lote first that if the conditional distribution of $\varepsilon$ is independent of $x$, then the neutrality of money prevails in our contract equilibrium because $a=0$. That is, prices adjust proportionately to changes in money and there are consequently no real 
effects. We focus on the case where an increase in money growth $(x)$ induces a mean preserving spread on the distribution of individual shifts (sae Rothschild and Stiglitz (1970) and Diamond and Stiglitz (1974)). Then, so long as $\mathrm{DV}$ is convex--as was required to insure that saving rises with increased income variability-it follows that E[DV]|x rises with $x$. That is, prices respond less than proportionately to a change in money growth because old agerts wish to purchase insurance against such aggregate states (i.e., a $>0$ in (13) above). ${ }^{7}$

Figures la,b show the relationship between money growth, contract prices and effort/production in our economy.

\section{Extensions and Modifications}

We now briefly consider several variations on the main theme of this paper, which are presently in the form of detailed conjectures.

First, suppose that we introduce two components of money growth, $x=x_{1} \bullet x_{2}$, where $x_{1}$ is correlated with the dispersion of individual shocks as above and $x_{2}$ is not. If agents know the separate realizations of $x_{1}$ and $x_{2}$, then the latter would be neutral, yielding proportionate changes in contract prices and no output effects. By contrast, if agents observe total money growth ( $x$ ) but not its individual components, then more interesting results should arise. That is, contract prices should continue to respond less than proportionately to changes in money growth, although more elastically than above because $x$ is only an imperfect indicator of $x_{1}$. Output would respond to total money

7 In Haubrich (1983), changes in an aggregate state variable alter the level of efficient risk pooling in the banking developed by Haubrich and King (1983). Here, by contrast, the aggregate state variable alters the extent of efficient risk shifting. In both cases, it is central that the aggregate shock have implications for the dispersion of individual circumstances. 
Figure 1a:

Money and Prices under Contracting

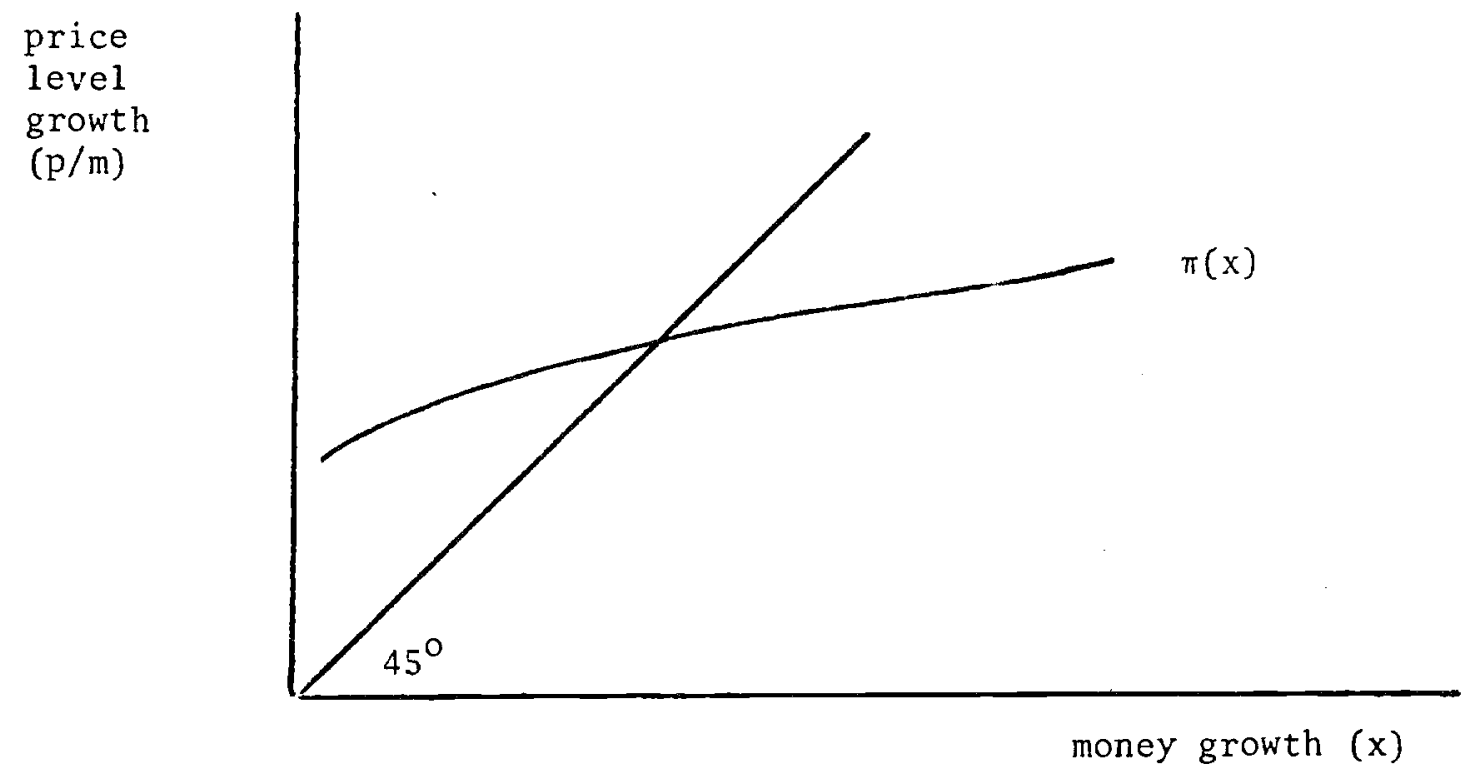

Figure 1b:

Money and Output under Contracting

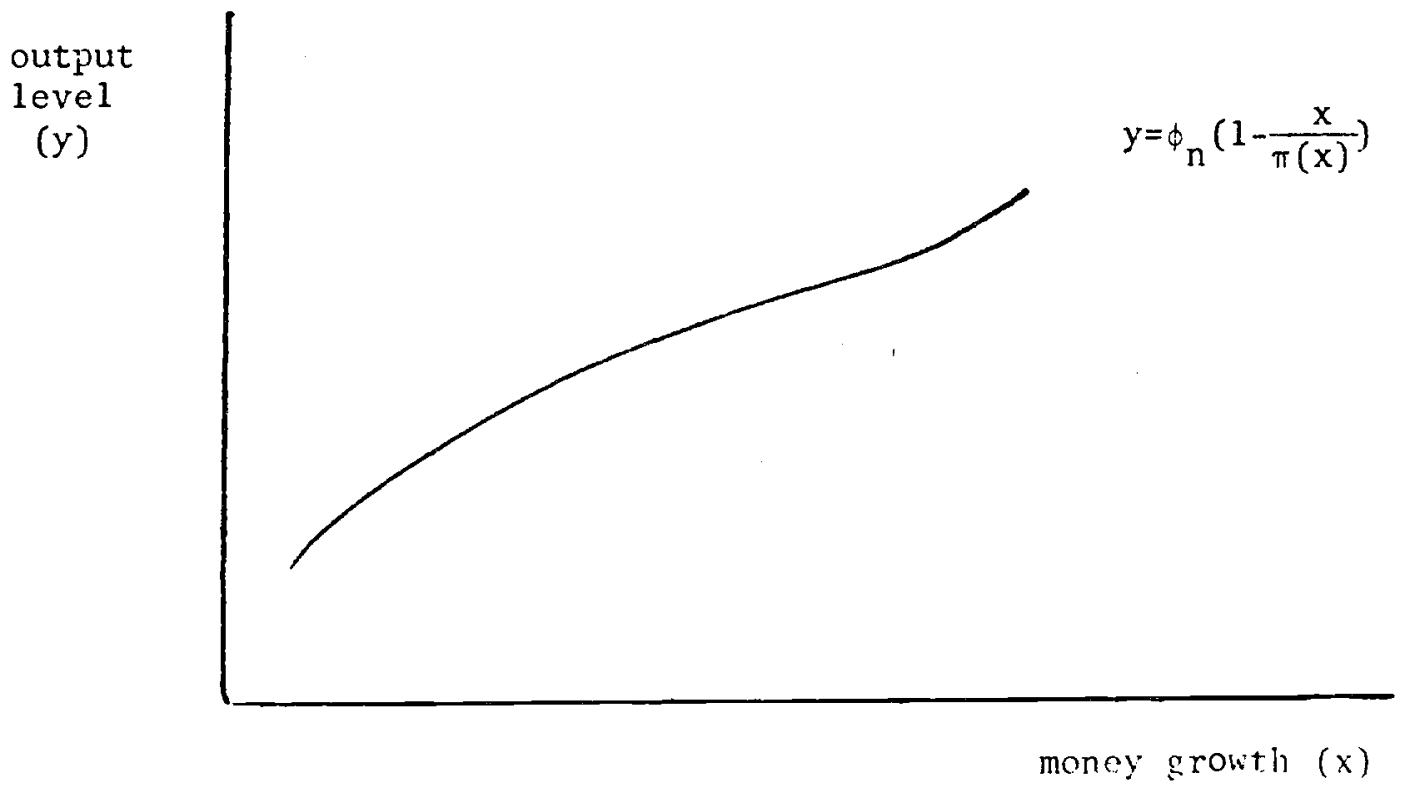


growth, although less elastically than above. If, as in King and Trehan (1983), one considers $x_{2}$ to be the policy component of money growth, then it follows that monetary policy actions will be nonneutral so long as agents cannot distinguish these from other monetary changes. ${ }^{8}$ However, the model should display a variant of Lucas's (1973) hypothesis on the Phillips curve slope because greater variability in the policy component $\left(x_{2}\right)$ should reduce the responsiveness of output to monetary shocks.

Second, suppose that we alter the form of our fiscal regime so that individual transfer payments are made in fixed nominal rather than real terms (e.g., transfers take the form $\varepsilon x m$, so that old age consumption becomes $c^{\prime}=\left[x^{\prime} \lambda+\varepsilon^{\prime} x^{\prime} m^{\prime}\right] / p^{\prime}$. Then, a higher price level reduces the variability of real individual circumstances. Under this specification, it appears that efficient contracts would make prices more than proportionately responsive to money growth if higher $x$ continues to increase the spread of the $\varepsilon$ ' distribution. Consequentiy, the money-real activity relationship would involve the opposite sign to that described above. The sensitivity of results suggests further study of alternative 'fiscal regimes' is warranted.

IV. Summary and Conclusions

This theoretical investigation has been conducted under two guiding principles. First, the enalysis of 'sticky prices' must be conducted in a general equilibrium setting, so as to assure consistent behavioral responses and to lay the groundwork for examination of policy alternatives in accordance with the Lucas (1976) critique. Typical sticky nominal price stories such as

8 Nevertheless, it should be the case that it will be desirable--as asserted by Barro (1976) in analys is of one of the classic imperfect information models-for the monetary authority to release information about $x_{2}$ to the private sector, which would render it neutral. 
Fischer (1977) postulate nominal contracts, exogenously imposing a pattern of arrangements on the labor market of an otherwise neoclassical model. There are no specific gains from nominai contracting at the private or social level identified by the models of Fischer (1977) et. al. Without an explicit framework that generates contracts endogenously, it is possible that such 'sticky price' models are internally inconsistent, since factors motivating a demand for a specified wage contract may also restrict employment or consumption decisions. ${ }^{9}$ Further, these results are devoid of predictions about how contracts will change in the face of variations in the economic environment. Second, in our view, the analysis of sticky nominal prices requires explicit consideration of a monetary economy. ${ }^{10}$ Further, there must be elements of real uncertainty that are associated with monetary movements, if nominal price stickiness is to be explained as a result of contractural arrangements that arise for risk allocating reasons.

With these guiding principles, we opted to study a stochastic consumption loans model that is a minor variation on Lucas (1972). In this setup, monetary growth was assumed to be positively related to the dispersion of individual transfer payments. Although money was fully neutral with an exogenous restriction on contracts, neutrality did not continue to prevail when the restriction was lifted. Rather, competitive contracts specified price stickiness--in the sense of less than proportionate adjustment in prices--and consequently a positive relationship between production and money growth. Thus, our model econony provides a counter-example to Barro's (1977)

- Hallace ( $197 i$ and elseinere) makes a general statement of the limitations of specification of behavior on an equation by equation basis, which he terms the 'macroeconomic approach'.

10 By contrast, many traditional casual explanations of price stickiness--such as those outlined by Okun (1980) and Gordon (1981)--are microeconomic, applying to relative rather than absolute prices. 
conjecture that efficient competitive contracts necessarily reduce the dependence of output on nominal money growth.

Finally, our model economy matches up with some of the features that McCallum (1982) identifies as central empirical elements of business fluctuations. Suppliers set prices (contingency plans) in advance of the realization of demand. ${ }^{11}$ High money growth does lead to high output, with one being able to argue that this occurs because prices don't adjust enough. At the same time, our model is not obviously Keynesian. That is, there are not important social costs of nominal contracting left uncontemplated in private arrangements.

11 But our prices are not predecermined. For one attempt at rationalizing that extreme form of stickiness, see Azariadis and Cooper (1983). 


\section{References}

Azariadis, C., "Escaletor Clauses and the Cyclical Allocation of Risks," Journal of Economic Theory, 18 (June 1978): 119-155.

and R. Cooper, "Predetermined Prices and the Allocation of Social Risks," Cowles Foundation Discussion Paper, No. 660, January 1983.

Barro, R.J., "Rational Expectations and the Role of Monetary Policy," Journal of Monetary Economics, 2 (January 1976):1-32.

Borch, K., "Equilibrium in a Reinsurance Market," Econometrica, 30 (July 1962) $: 424-444$.

Diamond, P. and J.E. Stiglitz, "Increases in Risk and in Risk Aversion," Journal of Economic Theory, 8 (July 1974): 337-360.

Gordon, R.J., "Output Eluctuations and Gradual Price Adjustment," Journal of Economic Literature, 19 (June 1981): 493-530.

Grossman, S.J., O. Hart, and E. Maskin, "Observable Aggregate Shocks with Unobservable Consequences," National Bureau of Economic Research Working Paper no. 975, September 1982.

Haubrich, J.G., "Sluggish Deposit Rates," Liniversity of Rochester, September 1983 .

and R.G. King, "Banking and Insurance," University of Rochester working paper 8̂-10, July 1983.

King, R.G. and B. Trehar. "The Implications of an Endogenous Yloney Supply for Monetary Neutrality, " Lniversity of Rochester working paper 83-12, July 1983.

Lucas, Robert E., "Expeczations and the leutrality of Money," Journal of Economic Theory, 4 (April 1972): 103-24.

"Some International Evidence on Output-Inflation Tradeoffs," American Economic Feriek, 63 (June 1973): 326-34.

, "Econometric Policy Evaluation: A Critique," in K. Brunner and A.H. Meltzer (eds.), The Phillips Curve and Labor Markets, CarnegieRochester Conference Series no. 1, Amsterdam: Torth Holland, 1976: $7-30$.

, "Methods and Problems in Business Cycle Theory," Journal of Money, Credit and Benking, 12 (November 1980, part 2): 696-715.

McCallum, B.T." ":Aacroeconomics After a Decade of Rational Expectations: Some Critical Issues," Federal Reserve Bank of Richmond Economic Reriew November/December 1982: 3-12. 
"A Linearized Version of Lucas's Neutrality Model," National Bureau of Economic Research Working Paper No. 1160, June 1983.

Okun, A.M., Prices and Quantities: A Macroeconomic Analysis, hashington: Brookings Institution: 1980.

Rothschild, M. and J.E. Stiglitz, "Increasing Risk I: A Definition," Journal of Economic Theory, 2 ( 1970): 225-243.

Sandmo, A., "The Effect of Uncertainty on Saving Decisions," Review of Economic Studies, 37 (July 1970): 353-360.

Takayama, A., Ylathematical Economics, Hinsdale, Illinois: The Drydon Press: 1974.

Townsend, R.Y., "Models of Money with Spatially Separated Agents," in J.H. Karaken and N. Wallace (eds.), Models of Monetary Economics, Federal Reserve Bank of Minneapolis, 1980.

Wallace, M. "Microeconomic Theories of Macroeconomic Phenomena and Their Implications for Monetary Policy," in A Prescription for Yonetary Policy: Proceedings from a Seminar Series, Federal Reserve Bank of Minneapolis, 1976. 


\section{Appendix}

In this appendix, we obtain the optimal contract for our model economy by solving an integral-constraint control problem. More specifically, we rely on methods provided by Takayama $[1974,8 \mathrm{c} . \mathrm{b}]$ in his discussion of Hestene's theorem.

Recall that the island's problem is to maximize young agent utility subject to the demand constraint that requires old agent utility to at least equal that achievable elsewhere. The problem is to choose the price function or, in particular, $\pi(x)$ so as to

$$
\max E\left\{w\left(1-\frac{x}{\pi(x)}\right)\right\}
$$

subject to $E\left\{v\left(\frac{x}{\pi(x)}+\varepsilon\right)\right\} \geq \bar{v}$.

Letting $h(x)$ be the density function of $x$ and letting $g(\varepsilon x)$ be the conditional density function of $\varepsilon$, the objective and constraint each take the form of an integral. Specifically, the constraint may be witten as

$$
\begin{array}{ll}
\bar{x} & \bar{\varepsilon} \\
f & \left\{\int\left[v\left(\frac{x}{\pi(x)}+\varepsilon\right)-\bar{v}\right] g(\varepsilon ; x) d \varepsilon\right\} h(x) d x \geq 0 . \\
x & \underline{\varepsilon}
\end{array}
$$

Forming the Hamiltonian according to Takayama's methods, we get

$$
\begin{aligned}
H(T(x), x)= & \rho H\left(1-\frac{x}{\pi(x)}\right) h(x) \\
& \quad \alpha \bar{\varepsilon} \\
& -\alpha\left\{\left[v\left(\frac{x}{\pi(x)}+\varepsilon\right)-\bar{v}\right] g(\varepsilon ; x) d \varepsilon\right\} h(x)
\end{aligned}
$$

12 If $x$ had a discrete distribution, $\rho$ and a would be a series of Lagrange multipliers, one pair for each point in the $x$ distribution. However, $a$ continuous $x$ distribution permits us to more readily discuss marginal changes, although it necessitates the control problem. 
where $p$ and $\alpha$ are multipliers. ${ }^{12}$ Since our problem is a variable righthand endpoint problem (i.e., $r(x)$ is not specified in advance), we can set $p=1$ in (A2) without loss of generality. Maximizing the Hamiltonian with respect to the control, $\pi(x)$, we obtain the necessary condition

$$
\begin{aligned}
\frac{\partial H}{\partial \pi}= & D_{H}\left(1-\frac{x}{\pi(x)}\right) h(x) \frac{x}{\pi(x)^{2}} \\
& -\frac{\varepsilon}{\varepsilon}\left[\int\left[D v\left(\frac{x}{\pi(x)}+\varepsilon\right) \cdot \frac{x}{\pi(x)^{2}}\right] g(\varepsilon ; x) d \varepsilon\right\} h \\
& -\alpha
\end{aligned}
$$

which implies the key condition (Borch's rule).

$$
\operatorname{Dw}\left(1-\frac{x}{\pi(x)}\right)=\alpha E\left[\operatorname{Dr}\left(\frac{x}{\pi(x)}+\varepsilon\right)\right] x
$$

that is equation (12) in tine main text.

12 If $x$ had a discrete distribution, $\rho$ and $\alpha$ would be a series of Lagrange multipliers, one pair for each point in the $x$ distribution. However, $a$ continuous $x$ distribution permits us to more readily discuss marginal changes, although it necessitates the control problem. 